\title{
Association of Hemoglobin during First Trimester and its Relation to Pregnancy-Induced Hypertension in Indian Women
}

\author{
Kamini Gajjar ${ }^{1}$ Anil Gajjar², Hasmukh Shah ${ }^{1, *}$
}

Kamini Gajjar1,

Anil Gajjar ${ }^{2}$, Hasmukh Shah ${ }^{1, *}$

\section{'Tutor, Department of Physiology, Pramukhswami Medical College, Karamsad, Gujarat, INDIA. \\ 2Gynaecologist, C G General Hospital, Uttarsanda, Gujarat, INDIA. \\ *Correspondence}

\section{Dr. Hasmukh Shah,}

Professor \& Head, Department of Physiology Pramukhswami Medical College, Karamsad, Anand, Gujarat: 388 325, INDIA.

Phone: +919879731388

Email: hasmukhds@charutarhealth. org

\section{History}

- Submission Date: 30-03-2020;

- Review completed: 23-05-2020;

- Accepted Date: 12-06-2020.

DOI : 10.5530/ijcep.2020.7.2.18

Article Available online

http://www.ijcep.org

\section{Copyright}

(c) 2020 Phcog.Net. This is an openaccess article distributed under the terms of the Creative Commons Attribution 4.0 International license.

\begin{abstract}
Background and Aim: Globally, prevalence of pregnancy-induced hypertension $(\mathrm{PIH})$ is $3-5 \%$ and in India it is around $5-15 \%$. PIH is one of the major factors responsible for abnormal pregnancy outcome along with high maternal and perinatal morbidity and mortality. Role of hemoglobin is the key factor for pregnancy outcome and development of hypertension during pregnancy. This study was done with aim to check the relation of maternal hemoglobin with blood pressure and development of PIH in Indian women of 20 to 30 years of age group. Methods: A cross sectional multicentric study was done after approval of Institutional Ethics Committee. A total 200 pregnant female visiting to antenatal clinics in age group of 20 to 30 years were enrolled after their written voluntary consent. Participant's body weight, hemoglobin, along with pulse rate, systolic blood pressure and diastolic blood pressure were done during $1^{\text {st }}$ antenatal visit at first trimester, during next visit at $2^{\text {nd }}$ trimester between $20^{\text {th }}$ to $24^{\text {th }}$ weeks and between $25^{\text {th }}$ to $28^{\text {th }}$ weeks during third trimester. During $1^{\text {st }}$ antenatal visit participants were categorized into two groups with hemoglobin less than $10 \mathrm{gm} \%$ and hemoglobin more than $10 \mathrm{gm} \%$ comprising 100 participants in each group. Progress of pregnancy was documented very well during subsequent next visit. All participants had visited antenatal clinic till delivery as per instructions given to them. Pregnancy outcomes were documented very well up to 6 week of delivery. Results: In participants of both groups, progressive increases in weight, hemoglobin, heart rate, systolic blood pressure, diastolic blood pressure were seen. A statistical significant difference in weight was seen in both groups during all trimester. A statistical significant difference in diastolic blood pressure was seen in both groups during $2^{\text {nd }}$ trimester. Total 17 participants developed $\mathrm{PIH}$, out of which 10 participants were from group 1, i.e. hemoglobin less than $10 \mathrm{gm} \%$ and 7 from group 2 with haemoglobin more than $10 \mathrm{gm} \%$. Conclusion: In the present study, role of maternal hemoglobin in development of pregnancy induced hypertension is not seen.
\end{abstract}

Key words: Hemoglobin, Anemia, Pregnancy Induced Hypertension, Pre-eclampsia.

\section{INTRODUCTION}

Pregnancy-induced hypertension (PIH) affects successful outcome of pregnancy and it is responsible for maternal, foetal and neonatal morbidity and mortality ${ }^{[1,2]}$ Maximum mortality is seen in triad of hypertension, haemorrhage and infection during pregnancy. ${ }^{[3,4]}$ Prevalence of pregnancy induced hypertension in developed countries is upto $20 \%$ and in developing countries is around 5-15\%. Approximately, 5-8\% of pregnant women globally and $5-15 \%$ of pregnant women in India are affected by pregnancy induced hypertension. ${ }^{[5,6]}$

Race and ethnicity of women play a significant role in prevalence of pregnancy induced hypertension. Approximately, in 6-10\% of diagnosed cases of PIH, complications are seen. The aetiology of pregnancy induced hypertension remains unclear but few pathophysiological correlations were established by scientists. Pregnancy induced hypertension is two times more common in primigravida in comparison to multigravida.

Cite this article: Gajjar K, Gajjar A, Shah H. Association of Hemoglobin during First Trimester and its Relation to Pregnancy-Induced Hypertension in Indian Women. Int J Clin Exp Physiol. 2020;7(2):73-6. 
High maternal hemoglobin during first trimester and development of hypertension was documented by few scientists. ${ }^{[10]}$ High maternal hemoglobin is a very common finding in developed countries with normal body mass index. Increased concentration of hemoglobin is the main cause of generalized vasoconstriction during pregnancy and for genesis of gestational hypertension. ${ }^{[8]}$ Anemia in pregnancy is a common finding in developing countries like India due to lower socioeconomic status. Physiologically, hemoglobin level decreases during first trimester, reaches the minimum values during late second trimester and further increase during third trimester of pregnancy. Association of maternal anemia with adverse pregnancy outcome is very well documented. Preterm birth, low birth weight (LBW), caesarean section (CS) and postpartum haemorrhage and infection were commonly seen in anaemic mother. ${ }^{[3,4]}$ Conflicting findings were seen in this regards. Relation of adverse pregnancy outcome with mild, moderate and severe anemia is controversial.

Anemia during first trimester of pregnancy and genesis of pregnancy induced hypertension is not well understood. Abnormally low and high hemoglobin together with eclampsia is a common cause of mortality in South Asia. ${ }^{[1]}$ High hemoglobin is rarely seen in Indian pregnant women. Though, increased maternal mortality due to postpartum haemorrhage and infection in anaemic women are common but their association with gestation hypertension is poorly documented. ${ }^{[3,4]}$ Therefore, association of $\mathrm{Hb}$ with blood pressure should be explored for prevention of high maternal mortality and for good pregnancy outcomes in anaemic pregnant women. Having a major role of hemoglobin and blood pressure on outcome of pregnancy, our study was conducted in the interest of finding the association of maternal hemoglobin and development of pregnancy induced hypertension in Indian women of age group ranging from 20 to 30 years.

\section{MATERIALS AND METHODS}

The study was approved by Institutional Ethics Committee, Pramukhswami Medical College, Karamsad. The study was conducted during January 2018 to July 2019 in Department of Obstetrics and Gynaecology (OBG), Shree Krishna Hospital, Pramukhswami Medical College, Karamsad, Akshardeep Hospital, Anand and C. G. General Hospital, Uttarsanda. Participants were informed about the detailed methodology of the study and the study protocol. Pregnant women in the age group of 20 to 30 years attending OBG Department for routine antenatal checkups were recruited for the study on voluntary basis after obtaining the written informed consent. Participants with history of hypertension, diabetes mellitus, dyslipidaemia, renal diseases, thyroid diseases or any other chronic diseases, family history of hypertension and diabetes were excluded from the study.

Assessment of each pregnant woman for anthropometry, haematological parameters and cardiovascular profile was done as per guideline of routine antenatal checkups. During the first antenatal visit in first trimester, each participant was assessed for anthropometric parameters like height and body weight by standard methods. The body weight (Wt) was recorded bare footed to the nearest $0.5 \mathrm{~kg}$. The height was measured using meter scale without footwear to the nearest $5 \mathrm{~cm}$. Cardiovascular parameters like pulse rate and blood pressure were taken after following all standard precautions. Pulse rate and Blood pressure were measured in the left arm in sitting position with arm and back support, uncrossed legs and feet on the floor using the Omron T8 (HEM757A4-C1) Automatic Blood Pressure instrument (Accuracy, BP: $\pm 4 \mathrm{~mm} \mathrm{Hg}$, Pulse: \pm 5 , validated by Association for the Advancement of Medical Instrumentation, AAMI and British Hypertension Society, BHS). Readings were taken at intervals of $1 \mathrm{~min}$ till the difference between two consecutive BP readings was less than $5 \mathrm{~mm} \mathrm{Hg}$. The average of the two consecutive readings was used for statistical analysis. Estimation of hemoglobin was done by automated analyzer instrument [ABX, MICROS 60]. ${ }^{[12,13]}$

Participants were categorized into two groups on the basis of their hemoglobin level at first antenatal visit as follows; Group 1 with hemoglobin level $<10 \mathrm{gm} \%$ and Group 2 with hemoglobin level $\geq 10 \mathrm{gm} \%$. All participants were advised and informed for their second antenatal visit between $20^{\text {th }}-24^{\text {th }}$ week of gestation and third antenatal visit between $25^{\text {th }}-28^{\text {th }}$ week during third trimester. All participants were assessed for body weight, pulse rate, blood pressure and hemoglobin level during second and third antenatal visit as per standard protocol. All participants had visited antenatal clinic till delivery as per instructions given to them. Pregnancy outcomes were documented very well up to 6 weeks following delivery.

\section{Statistical Analysis of Data}

Data was entered in Microsoft Excel 2010 and analysed using SPSS, version 15. All the data was expressed as mean \pm SD. Quantitative data of two groups were compared by independent sample $t$-test. Qualitative data was presented as frequency and percentage and compared using Chi square test. $P$ value $<0.05$ was considered statistically significant. A multivariable logistic regression was done with backward LR method.

\section{RESULTS}

Table 1 shows the comparison of maternal anthropometric, haematological and cardiovascular parameters between Group 1 with hemoglobin level $<10$ gm $\%$ and Group 2 with hemoglobin level $\geq 10 \mathrm{gm} \%$. In participants of both groups, progressive increase in weight, hemoglobin, pulse rate, systolic blood pressure, diastolic blood pressure were seen. A statistical significant difference in weight was seen in both groups during all trimester. Pulse rate and systolic blood pressure were high in Group 2 with hemoglobin level $\geq 10 \mathrm{gm} \%$ in comparison to Group 1 with hemoglobin level $<10$ gm\% during all three trimesters, but statistically not significant. Diastolic blood pressure was high in Group 2 with hemoglobin level $\geq 10 \mathrm{gm} \%$ in comparison to Group 1 with hemoglobin level $<10$ gm\% during all three trimesters, but statistically significant only during $2^{\text {nd }}$ trimester.

According to the details given in Table 2 and Table 3, total 17 pregnant (8.5\%) women developed PIH. Out of which,10 pregnant women (59\% of PIH women) in Group 1 with hemoglobin level $<10 \mathrm{gm} \%$ and 7 pregnant women ( $41 \%$ of PIH women) in Group 2 with hemoglobin level $\geq 10 \mathrm{gm} \%$. As per the results of chi-square test, there was no association between the haemoglobin in the first trimester and occurrence of pregnancy induced hypertension in both the groups ( $p$ value $>0.05$ ).

Trimester wise comparison of weight, pulse rate, SBP, DBP and $\mathrm{Hb}$ among those who developed PIH and those who did not develop PIH was displayed in Table 4. Weight was not significantly differing in any trimester between PIH and Non-PIH group. Similar findings were observed for pulse rate and $\mathrm{Hb}$. However, SBP was significantly higher in $3^{\text {rd }}$ trimester in PIH group $(121.2 \pm 17.35 \mathrm{mmHg})$ compared to nonPIH group $(109.9 \pm 11.61 \mathrm{mmHg})$. DBP was also significantly higher in $3^{\text {rd }}$ trimester in PIH group $(74.2 \pm 18.41 \mathrm{mmHg})$ compared to non-PIH group $(68.7 \pm 9.46 \mathrm{mmHg})$.

A multivariable logistic regression model (with backward LR method) was generated to understand individual contribution of different parameters (weight, pulse rate, SBP, DBP and hemoglobin of all three trimester) on developing PIH. Logistic regression revealed that incidence of PIH was not associated with hemoglobin level. ( $p$ value $>0.05$ ). 
Table 1: Trimester wise comparison of maternal variables between two groups according to $\mathbf{H b}$.

\begin{tabular}{|c|c|c|c|c|c|c|}
\hline \multirow[t]{2}{*}{ Variable } & \multirow{2}{*}{$\begin{array}{c}\text { Trimester } \\
1^{\text {st }}\end{array}$} & \multicolumn{2}{|c|}{ Group 1 with Hemoglobin level < $10 \mathrm{gm} \%$} & \multicolumn{2}{|c|}{ Group 2 with Hemoglobin level >10 gm\% } & \multirow{2}{*}{$\begin{array}{c}\boldsymbol{p} \text { value } \\
<0.05\end{array}$} \\
\hline & & 45.3 & 8.06 & 48.4 & 10.04 & \\
\hline \multirow[t]{2}{*}{ Weight } & $2^{\text {nd }}$ & 48.9 & 7.65 & 51.9 & 10.23 & $<0.05$ \\
\hline & $1^{\text {st }}$ & 94.0 & 9.36 & 94.9 & 10.28 & $>0.05$ \\
\hline Pulse Rate & $2^{\text {nd }}$ & 95.2 & 11.23 & 95.1 & 10.62 & $>0.05$ \\
\hline \multirow[t]{3}{*}{ SBP } & $2^{\text {nd }}$ & 107.4 & 10.38 & 109.0 & 11.35 & $>0.05$ \\
\hline & $3^{\text {rd }}$ & 110.7 & 13.01 & 111.1 & 12.13 & $>0.05$ \\
\hline & $1^{\mathrm{st}}$ & 67.0 & 10.08 & 67.1 & 11.72 & $>0.05$ \\
\hline DBP & $2^{\text {nd }}$ & 65.0 & 8.83 & 68.0 & 7.92 & $<0.05$ \\
\hline Hemoglobin & $3^{\text {rd }}$ & 10.7490 & 1.20374 & 10.6940 & 1.21679 & $>0.05$ \\
\hline
\end{tabular}

SBP: Systolic blood pressure; DBP: Diastolic blood pressure. $P<0.05$ is considered to be statistically significant.

Table 2: Distribution of patients according to PIH.

\begin{tabular}{ccc|}
\hline PIH & Frequency & Percentage (\%) \\
Yes & 17 & 8.5 \\
No & 183 & 91.5 \\
Total & 200 & 100.0 \\
\hline
\end{tabular}

Table 3: Prevalence of Pregnancy induced hypertension between two groups.

\begin{tabular}{|ccccc|} 
PIH & $\begin{array}{c}\text { Group 1 with } \\
\text { Hemoglobin level } \\
<10 \text { gm } \%\end{array}$ & $\begin{array}{c}\text { Group 2 with } \\
\text { Hemoglobin level } \\
>10 \text { gm } \%\end{array}$ & Total & $\begin{array}{c}\text { Chi square } \\
\text { and } \\
p \text { value }\end{array}$ \\
\hline Yes & 10 & 7 & 17 & $\mathrm{X}^{2}=0.58$ \\
No & 90 & 93 & 183 & $\mathrm{p}=0.61$ \\
& 100 & 100 & 200 & \\
\hline
\end{tabular}

\section{DISCUSSION}

The present study showed that a pregnant woman with lower hemoglobin concentration during first trimester was associated with high risk for development of PIH. Cardiovascular parameters like HR, SBP, DBP were increased in group 2 with hemoglobin level $\geq 10$ gm $\%$ in comparison to group 1 with hemoglobin level $<10$ gm $\%$ during all the three trimesters. Similarly, more weight was seen in group 2 in comparison to group 1 during all trimesters. Though weight and blood pressure were increased in pregnant women with hemoglobin level $\geq 10 \mathrm{gm} \%$, development of $\mathrm{PIH}$ in this group was less (7 participants; $3.5 \%$ ) in comparison to Group 1 with hemoglobin level $<10$ gm\% (10 participants; 5.0\%). Our finding failed to show association of maternal hemoglobin in first trimester of pregnancy with development of pregnancy induced hypertension.

Muphy et al. explained that the various levels of hemoglobin in the first and second trimesters were related to preeclampsia. ${ }^{[10]}$ Sarrel et al. showed that there isa relation between increased free hemoglobin concentration and preeclampsia. ${ }^{[14]}$ Sarrel et al. also hypothesized that increased haemoglobin level leads to vasoconstriction induced hypertension.
Table 4: Trimester wise comparison of variable between two groups according to PIH.

\begin{tabular}{ccccccc}
\multirow{5}{*}{ Variable } & \multicolumn{5}{c}{ Pregnancy Induced Hypertension } \\
& Trimester & \multicolumn{2}{c}{ Yes $(\boldsymbol{n}=17)$} & No $(\boldsymbol{n}=183)$ & p value \\
& & Mean & SD & Mean & SD & \\
Weight & $1^{\text {st }}$ & 45.2 & 7.93 & 47.0 & 9.32 & $>0.05$ \\
& $2^{\text {nd }}$ & 48.5 & 8.46 & 50.6 & 9.19 & $>0.05$ \\
& $3^{\text {rd }}$ & 51.7 & 8.77 & 54.6 & 10.01 & $>0.05$ \\
Pulse Rate & $1^{\text {st }}$ & 92.6 & 11.35 & 94.6 & 9.68 & $>0.05$ \\
& $2^{\text {nd }}$ & 92.8 & 12.12 & 95.4 & 10.79 & $>0.05$ \\
& $3^{\text {rd }}$ & 91.9 & 13.80 & 98.1 & 10.63 & $>0.05$ \\
SBP & $1^{\text {st }}$ & 110.5 & 8.68 & 106.6 & 9.55 & $>0.05$ \\
& $2^{\text {nd }}$ & 110.5 & 9.86 & 108.0 & 10.97 & $>0.05$ \\
& $3^{\text {rd }}$ & 121.2 & 17.35 & 109.9 & 11.61 & $<0.05$ \\
DBP & $1^{\text {st }}$ & 70.8 & 13.54 & 66.7 & 10.61 & $>0.05$ \\
& $2^{\text {nd }}$ & 65.5 & 9.62 & 66.6 & 8.41 & $>0.05$ \\
& $3^{\text {rd }}$ & 74.2 & 18.41 & 68.7 & 9.46 & $<0.05$ \\
& $1^{\text {st }}$ & 10.0 & 1.37 & 9.97 & 1.45 & $>0.05$ \\
Hemoglobin & $2^{\text {nd }}$ & 10.11 & 1.15 & 10.14 & 1.29 & $>0.05$ \\
& $3^{\text {rd }}$ & 10.81 & 1.53 & 10.71 & 1.17 & $>0.05$
\end{tabular}

SBP: Systolic blood pressure; DBP: Diastolic blood pressure.

$\mathrm{P}<0.05$ is considered to be statistically significant.

A generalized vasoconstriction and abnormal endothelial cell functions are mainly due to high free hemoglobin and it is considered to be a causative factor for development of PIH. Fall in hemoglobin concentration from first trimester to second trimester is mainly due to expansion to plasma volume. A threefold increase of pre-eclampsia in pregnancy is mainly due to failure of expansion of plasma volume. ${ }^{[15]}$ Aghamohammadi A et al. reported that high maternal hemoglobin concentration in first trimester is a risk factor for pregnancy induced hypertension. ${ }^{[8]}$ 
Abdel Aziem et al. mentioned that risk of development of preeclampsia was 3.6 times higher in women with severe anemia in comparison to women with no anemia. ${ }^{[16,17]}$ Rohilla $\mathrm{M}$ et al. also explained about severe anaemia and its relation in development of preeclampsia. ${ }^{[18]}$ In anaemic women, coexisting deficiency of micronutrients and antioxidants were also responsible for development of pregnancy induced hypertension. Results from the study by Jain $S$ et al. showed that reduction in serum levels of calcium, magnesium and zinc during pregnancy might be one of the contributors to the development of preeclampsia. ${ }^{[19]}$ Murphy et al. showed that the frequency of hypertension increased from $7 \%$ with $\mathrm{Hb}<10.5 \mathrm{~g} / \mathrm{dl}$ to $42 \%$ with $\mathrm{Hb}>14.5 \mathrm{~g} / \mathrm{dl}$ in primigravida. ${ }^{[10]}$

Hamideh Pakniat et al. showed significant association of first trimester hemoglobin, hematocrit and preeclampsia. ${ }^{[20]}$ Safavi et al. showed a significant association between high hematocrit during first trimester and development of preeclampsia. ${ }^{[21]}$ Bouzari et al. also showed the higher hematocrit during first trimester and causation of preeclampsia. ${ }^{[22]}$ Our results, did not match with the results of above mentioned studies. But, incidence of pregnancy induced hypertension in our study was around $8.5 \%$ and it was supported by Indian studies by Mudaliar and Menon. They reported that incidence of preeclampsia ranges between $7-9 \% .{ }^{[23]}$ Jaiprakash et al. reported that incidence of preeclampsia is $5.8 \%$ and in another study by Garima Gupta also reported that incidence of preeclampsia in Bhopal was 5.8\%. ${ }^{[24,25]}$ Globally, pre-eclampsia affects approximately $2-8 \%$ of all pregnancies. ${ }^{[6]}$

Strength of this study is that a longitudinal data obtained throughout all trimester of pregnancy. Anemia is very common findings in Indian women during pregnancy, so authors tried to address this issue very well. Limitation of this study is that a longitudinal study with a large sample size is needed to explore whether mild, moderate or severe anaemia a possible cause of pregnancy induced hypertension. Another limitation of the study is that the association of higher hemoglobin level with PIH is not taken into consideration. Though present study failed to find any relation of hemoglobin with pregnancy induced hypertension, future studies should address the link of hemoglobin products or glycated hemoglobin in comorbidities such as gestational hyperglycemia or oxidative stress associated with PIH.

\section{CONCLUSION}

We conclude that prevalence of pregnancy induced hypertension is approximately $8.5 \%$. In present study, role of maternal hemoglobin in development of pregnancy induced hypertension could not be seen. In future, a larger cohort with longer duration is needed to make future preventive strategy for early detection and management of hypertension in pregnant women.

\section{ACKNOWLEDGEMENT}

The authors are thankful to our parent organization Charutar Arogya Mandal, Karamsad, for providing a platform for the study. The authors are thankful to Dr. Smruti Vaishnav, Dr. Nitin Raithatha and Dr. A.R. Nair for their continuous support and guidance. The authors are obliged to our participants, without them this study was not possible.

\section{CONFLICT OF INTEREST}

The authors declare that they have no conflict of interest.

\section{ABBREVIATIONS}

PIH: Pregnancy Induced Hypertension; LBW: Low Birth Weight; CS: Caesarean Section; SBP: Systolic Blood Pressure; DBP: Diastolic Blood pressure.

\section{REFERENCES}

1. Cunningham FG, Leveno KJ, Bloom SL, Dashe JS, Hoffman BL, Casey BM, et al. Williams's obstetrics. Hypertensive Disorders. 22 ${ }^{\text {nd }}$ Ed. New York: McGraw-Hill Inc. 2005;567-80.

2. Sibai B, Dekker G, Kupferminc M. Pre-eclampsia. Lancet. 2005;365:785-99.

3. Chaim SR, Oliveira SM, Kimura AF. Pregnancy-induced hypertension and the neonatal outcome. Acta Paulista De Enfermagem. 2008;21(1):53-8.

4. Wang $C$, Lin L, Su R, Zhu W, Wei Y, Yan J, et al. Hemoglobin levels during the first trimester of pregnancy are associated with the risk of gestational diabetes mellitus, pre-eclampsia and preterm birth in Chinese women: A retrospective study. BMC Pregnancy and Childbirth. 2018;18(1):263-74.

5. Karthiga K, Pal GK, Velkumary S, Papa D, Palanivel C, Nanda N, et al. Sympathovagal Imbalance, Decreased Baroreflex Sensitivity and Increased Myocardial Work Stress in Pregnant Women with Risk of Developing Gestational Hypertension: A Preliminary Report. Int J Clin Exp Physiol. 2019;6(2):71-4.

6. World Health Organization (WHO). World health report 2005: Make every mother and child count. Geneva: WHO. 2005;63.

7. Lam C, Lim KH, Karumanchi SA. Circulating angiogenic factors in the pathogenesis and prediction of preeclampsia. Hypertension. 2005;46(5):1077-85.

8. Aghamohammadi A, Zafari M, Tofighi M. High maternal hemoglobin concentration in first trimester as risk factor for pregnancy induced hypertension. Caspian J Intern Med. 2011;2(1):194-7.

9. Garn SM, Ridella SA, Petzold AS, Falkner F. Maternal hematologic levels and pregnancy outcomes. Semin Perinatol. 1981;5(2):155-62.

10. Murphy JF, O'Riordan J, Newcombe RG, Coles EC, Pearson JF. Relation of haemoglobin levels in first and second trimesters to outcome of pregnancy. Lancet. 1986;327(8488):992-5.

11. Wang A, Rana S, Karumanchi SA. Preeclampsia: The Role of Angiogenic Factors in its Pathogenesis. Physiology. 2009;24(3):147-58.

12. Manjunatha $S$, Bennal AS. High maternal haemoglobin and its relation to pregnancy induced hypertension. Int J Rep Contracep Obstet Gynecol. 2015;4(6):1747.

13. Program $\mathrm{NH}$. Report of the national high blood pressure education program working group on high blood pressure in pregnancy. Am J Obstet Gynecol. 2000;183(1):s1-22.

14. Sarrel PM, Lindsay DC, Poole-Wilson PA, Collins P. Hypothesis: Inhibition of endothelium-derived relaxing factor by haemoglobin in the pathogenesis of pre-eclampsia. Lancet. 1990;336(8722):1030-2.

15. Manjunatha S, Amruta SB, Takilkar RH. First trimester high maternal haemoglobin-an independent risk factor for pre-eclampsia (PIH). Sch J App Med Sci. 2015:3:2558-60.

16. Ali AA, Adam I. Anaemia and stillbirth in Kassala hospital, eastern Sudan. JTrop Pediatr. 2011;57(1):62-4

17. Ali AA, Rayis DA, Abdallah TM, Elbashir MI, Adam I. Severe anaemia is associated with a higher risk for preeclampsia and poor perinatal outcomes in Kassala hospital, eastern Sudan. BMC Research Notes. 2011;4(1):311.

18. Rohilla M, Raveendran A, Dhaliwal LK, Chopra S. Severe anaemia in pregnancy: A tertiary hospital experience from northern India. J Obstet Gynaecol. 2010;30(7):694-6

19. Jain S, Sharma P, Kulshreshtha S, Mohan G, Singh S. The role of calcium, magnesium and zinc in pre-eclampsia. Biol Trace Elem Res. 2010;133(2):162-70.

20. Pakniat H, Movahed F, Bahman A, Azoor M. The Prediction of Preeclampsia and Its Association with Hemoglobin and Hematocrit in the First Trimester of Pregnancy. Biotech Health Sci. 2016;3(3):31-6.

21. Majd HA. The relationship between hemoglobin and hematocrit in the first trimester of pregnancy and preeclampsia. Arak Medical Uni J. 2011;14(4):1-9.

22. Bouzari Z, Yazdani $\mathrm{CH}$, Mohammadnetadj $\mathrm{M}$, Betiar $\mathrm{M}$. Association of hemoglobin and hematocrit of first and second trimesters of pregnancy with pre-eclampsia. J Babol Univ Med Sci. 2013;15(5):32-8.

23. Mudaliar, Menon. The evaluation of treatment of eclampsia. Brit J Obstet Gynaecol. 1961;68:417.

24. Prakash J, Vohra R, Pandey LK, Niwas SS, Behura SK, Singh U. Spectrum of kidney diseases in patients with preeclampsia-eclampsia. J Assoc Physicians. 2010;58:543-6.

25. Gupta G. A case control study to evaluate correlation of anemia with severe preeclampsia. Int J Reprod Contracept Obstet Gynecol. 2018;7(7):2773-7.

Cite this article: Gajjar K, Gajjar A, Shah H. Association of Hemoglobin during First Trimester and its Relation to Pregnancy-Induced Hypertension in Indian Women. Int J Clin Exp Physiol. 2020;7(2):73-6. 